\title{
Canadian Physicians' Use of Antiobesity Drugs and Their Referral Patterns to Weight Management Programs or Providers: The SOCCER Study
}

\author{
R. S. Padwal, ${ }^{1,2}$ S. Damjanovic, ${ }^{3}$ K. M. Schulze, ${ }^{4}$ R. Z. Lewanczuk, ${ }^{1}$ D. C. W. Lau, ${ }^{5}$ \\ and A. M. Sharma ${ }^{1}$ \\ ${ }^{1}$ Department of Medicine, University of Alberta, Edmonton, AB, Canada T6G 2V2 \\ ${ }^{2}$ Department of Medicine, Walter C. MacKenzie Health Sciences Center (2F1.26), \\ University of Alberta Hospital, 8440-112 Street, Edmonton, AB, Canada T6G 2B7 \\ ${ }^{3}$ Madella Clinical Research Consulting, Hamilton, Ontario, Canada L9C 7W6 \\ ${ }^{4}$ Population Health Research Institute, McMaster Hamilton, University Health Sciences, Hamilton, ON, Canada L8L $2 X 2$ \\ ${ }^{5}$ Department of Medicine, University of Calgary, Calgary, AB, Canada T2N 4N1
}

Correspondence should be addressed to R. S. Padwal, rpadwal@ualberta.ca

Received 13 September 2010; Accepted 15 October 2010

Academic Editor: A. Halpern

Copyright ( 2011 R. S. Padwal et al. This is an open access article distributed under the Creative Commons Attribution License, which permits unrestricted use, distribution, and reproduction in any medium, provided the original work is properly cited.

Antiobesity pharmacotherapy and programs/providers that possess weight management expertise are not commonly used by physicians. The underlying reasons for this are not known. We performed a cross-sectional study in 33 Canadian medical practices (36 physicians) examining 1788 overweight/obese adult patients. The frequency of pharmacotherapy use and referral for further diet, exercise, behavioral management and/or bariatric surgery was documented. If drug treatment or referral was not made, reasons were documented by choosing amongst preselected categories. Logistic regression models were used to identify predictors of antiobesity drug use. No single antiobesity management strategy was recommended by physicians in more than $50 \%$ of patients. Referral was most common for exercise (49\% of cases) followed by dietary advice (46\%), and only $5 \%$ of eligible patients were referred for bariatric surgery. Significant predictors of initiating/continuing pharmacotherapy were male sex (OR 0.70; $95 \%$ CI 0.52-0.94), increasing BMI (1.02; 95\% CI 1.01-1.03), and private drug coverage (1.78; 95\% CI 1.39-2.29). "Not considered" and "patient refusal" were the main reasons for not initiating further weight management. We conclude that both physician and patient factors act as barriers to the use of weight management strategies and both need to be addressed to increase uptake of these interventions.

\section{Introduction}

Excess body weight affects 1.6 billion individuals globally [1], is associated with substantial premature morbidity and mortality [2, 3], impairs quality of life [4], and accounts for $2 \%-7 \%$ of direct healthcare spending in developed nations [5]. Sixty-six $\%$ and $60 \%$ of the adult population in the US and Canada, respectively, are overweight (body mass index $\left.(\mathrm{BMI}) \geq 25 \mathrm{~kg} / \mathrm{m}^{2}\right)$ or obese $\left(\mathrm{BMI} \geq 30 \mathrm{~kg} / \mathrm{m}^{2}\right)[6,7]$.

Despite the increasing recognition of obesity as a public health problem and the well-documented benefits of even modest weight loss on comorbidities [7], there is concern that obesity is underreported and undertreated by healthcare professionals. Although weight loss counseling increases the likelihood of attempted weight loss by 3 -fold [8], only $43 \%$ of obese participants in a nationally representative survey of US adults reported receiving this intervention during their annual checkup [9]. At odds with patient perceptions is the finding that $75 \%$ of physicians report "always" or "nearly always" administering weight management counseling to their overweight or obese patients [10].

It also appears that, even among physicians who are providing weight management counseling to their patients, additional treatment options such as pharmacotherapy or referral to an additional program or provider are often not used [10, 11]. Weight management strategies such as 
expert-led diet and exercise counseling, commercial weight loss programs, pharmacotherapy, and behavioural therapy are recommended by current guidelines [7], and each can reduce weight by a clinically significant amount (at least $3 \%-5 \%$ of initial weight), which is associated with improvements in cardiovascular risk factors [12-15]. A recent study reported the following rates of referral/use: dietician $(67 \%)$, commercial weight loss program (59\%), exercise specialist (34\%), and pharmacotherapy (29\%) [10]. In a survey of 18 primary care practices in the US, only $14 \%$ of overweight or obese patients received a referral for further weight management [16].

Prior studies in this area have been retrospective in nature and thus potentially subject to recall bias $[10,16]$. They have also not attempted to examine underlying reasons why physicians are not using these antiobesity management strategies. This report details the major findings of the State of Obesity Care in Canada Evaluation Registry (SOCCER) study, which was designed to examine in closer detail Canadian physicians' use of antiobesity pharmacotherapy and referral patterns to additional obesity management programs and providers.

\section{Methods}

2.1. Participating Practices and Patient Recruitment. Registration in a provincial registry is a mandatory requirement for all practicing physicians in Canada. Accordingly, provincial medical registries were used to identify all primary care and specialist physicians across Canada in 2005-2007. Approximately 2000 physicians were contacted by phone, fax and/or E-mail, and the 50 physicians across 45 medical practices that agreed to participate were sent study materials, including the study protocol, case report forms, and enrolment logs. Physicians received telephone instructions describing the proper procedure for recruiting patients and populating study forms. This included reading through the entire study form with the physician to ensure that accurate information was collected for each question. No specific instructions or education regarding weight management practices were provided to the physicians. Thirty-six physicians from 33 of the 45 sites ( 27 primary care and 6 specialist practices) recruited participants. The specialist practices consisted of endocrinologists, cardiologists, and/or general internists (who provide consultative specialty care within the Canadian health care system rather than primary care).

2.2. Inclusion and Exclusion Criteria. Consecutive patients $\geq 18$ years with BMI levels $\geq 27 \mathrm{~kg} / \mathrm{m}^{2}$ who were able to provide informed consent were eligible for inclusion. A BMI threshold of $27 \mathrm{~kg} / \mathrm{m}^{2}$ was chosen instead of $25 \mathrm{~kg} / \mathrm{m}^{2}$ to increase the likelihood that patients were truly overweight (because BMI is an indirect measure of body fat) and because this cutoff is congruent with current recommendations for initiating drug therapy [7]. Patients were also required to have at least one indication for weight management, as judged by their physician.

Consecutive subjects seen during routine clinic operation and identified on predefined recruitment days were asked to participate. A patient could only be enrolled once in the study. Patients that were already participating in a clinical trial, hospitalized, pregnant, nursing, or unable to attend followup visits were excluded.

2.3. Assessment of Obesity Management Strategies. Because each patient enrolled was deemed by the physician to require weight management, it was assumed that the physician would provide some counseling at the encounter. However, no prior instructions were given to standardize the weight management advice given. The focus of SOCCER was to identify whether or not at this visit the physician initiated or continued obesity pharmacotherapy for a given patient and whether or not the physician referred the patient for further weight management. If referral was made, the type of weight management strategy or strategies involved was recorded. The weight management strategies examined included dietary counseling, commercial weight loss program/popular diet, exercise program (e.g., a trainer or gym membership), behavioral therapy (e.g., psychologist), and bariatric surgery. Depending on the strategy, referral could take the form of explicit written communication to another provider (e.g., surgery) or simply consist of verbal instructions to the patient to seek a specific type of treatment (e.g., commercial weight loss program). In the case of bariatric surgery, data collection was limited to those individuals considered potentially eligible for surgery (BMI $\geq 35 \mathrm{~kg} / \mathrm{m}^{2}$ ) [7].

Patients did not fill out any forms; forms were populated solely by physicians, and each physician was instructed to consider each weight management strategy in sequence and perform data entry in real time during the actual visit. For pharmacotherapy, physicians were asked to indicate if the patient will "start or continue pharmacotherapy TODAY". For the other weight management strategies, such as dietary counseling, instructions to the physician read as follows: "please indicate if you referred the patient for Dietary Counseling as a weight management strategy TODAY." Demographic information, employment status, medical history, physical examination, and current medications were also recorded at the time of the visit. In addition, physicians were asked to document if the reason for the referral was patient initiated and to provide the primary reason if referral was not made for a given strategy, choosing from the following categories (using check boxes): "patient refused", "not affordable", "not feasible", "past treatment failed", "contraindicated", and "not considered."

2.4. Predictors of Antiobesity Drug Use. An additional goal of SOCCER was to identify predictors of antiobesity drug use. Covariate-adjusted, binary logistic regression models were created to identify these predictors. Age, sex, BMI (per unit increase), ethnicity, type of practice (primary care versus specialist), supplemental health insurance, employment status (employed versus unemployed), gender concordance between patients and physicians (concordant versus discordant), and additional covariates that achieved a Wald Chisquare $P$-value significance level of .1 univariately were also considered. The final model was created using a backwards 
selection method to determine which of these additional covariates contributed to the model at a Wald Chi-square $P$-value of .1. Supplemental health insurance indicates the presences of private health coverage, which is primarily used to cover drug expenses. Sibutramine and orlistat are not covered by Canadian provincial health care plans and therefore patients typically pay out of pocket or through private insurance for these medications.

2.5. Data Collection and Statistical Analysis. Paper-based case report forms were populated at point-of-care, faxed to the project management centre (Population Health Research Institute, McMaster University) and optically scanned using DataFax (Clinical DataFax Systems Inc., Hamilton, Ontario). The forms were reviewed for missing, illegible, or contradictory data input. All of the data management processes followed written standard operating procedures (SOPs) and conformed to Good Clinical Practice (GCP) standards for the conduct and data management of clinical studies.

Statistical analysis was performed using SAS, version 9.1 (SAS Institute, Cary, NC). For all statistical tests, twotailed $P$ values less than .05 were considered statistically significant. Survey methods (PROC SURVEYLOGISTIC) account for the clustering of patients within individual physician practices [17]. With the exception of one practice that contained three physicians, only one physician per practice participated in the study. Furthermore, in the multiphysician practice, there were no differences in the use of pharmacotherapy or referral practices among the three physicians. Therefore, it was not necessary to control for physician clustering within practices.

2.6. Ethics Approval. Ethics approval was obtained from both the Canadian Shield Research Ethics Board and the Research Ethics Board of McMaster University, Hamilton Health Sciences.

2.7. Funding. SOCCER was funded by an unrestricted Grant from Abbott Laboratories Canada. The design, conduct and analysis of the study were carried out independently of the study sponsor.

\section{Results}

3.1. Study Population and Comorbidities. Thirty-six physicians enrolled 1904 patients across 33 participating sites in 7 provinces. $108(5.7 \%)$ did not have an indication for obesity management or meet age or BMI inclusion thresholds and were excluded. Eight patients were excluded because of missing BMI data, leaving 1788 patients included in the final analysis. Patients enrolled from specialty practices had higher mean BMI levels and greater comorbidity compared to patients seen in primary care practices (Table 1). The most common comorbidities were hypertension (48\%), dyslipidemia (43\%), osteoarthritis (27\%), back pain $(29 \%)$, and type-2 diabetes (24\%).

The percentage of patients with $0,1,2,3$, or $>3$ comorbidities was $14.2 \%, 17.6 \%, 16.0 \%, 16.5 \%$, and $35.7 \%$, respectively.
3.2. Use of Pharmacotherapy and Referral for Other Obesity Management Strategies. Pharmacotherapy was initiated or continued in only $21 \%$ of cases (39\% were by patient request). The frequencies of referral for $0,1,2$, or $>2$ weight management strategies (including use of pharmacotherapy) were $29.0 \%, 22.8 \%, 26.2 \%$, and $22.0 \%$, respectively. Overall, referral was most common for exercise, in $49 \%$ of cases, followed by dietary advice, in $46 \%$ of cases. Only $5 \%$ of eligible patients were referred for bariatric surgery (Table 2).

Predictors of initiating/continuing pharmacotherapy are summarized in Table 3. In the multivariable adjusted model, male sex (OR 0.70; 95\% CI 0.52-0.94) was associated with a lower likelihood whereas increasing BMI $(1.02 ; 95 \% \mathrm{CI}$ 1.01-1.03) and private drug coverage (1.78; 95\% CI 1.392.29) were associated with a greater likelihood of initiating or continuing antiobesity drug therapy.

3.3. Reasons for Lack of Referral. In all cases, physicians listed "not considered" as the main reason for not using pharmacotherapy (44\% of cases) or not referring a patient additional weight management $(32 \%-65 \%$ of cases and highest for bariatric surgery, Table 2). The second most common reason overall for lack of referral was patient refusal and in the cases of referral for diet, exercise and behavioral therapy, "not feasible" was also cited as a reason in substantial minority of cases (Table 2). "Past treatment failed", "not affordable", and "contraindicated" were cited in only a minority of cases.

\section{Discussion}

In summary, in this study of 36 physicians seeing nearly 1800 patients specifically identified as requiring weight management, antiobesity pharmacotherapy was used in only $21 \%$ of cases. Furthermore, referral to additional weight management provider or programs was recommended less than $50 \%$ of the time. Physicians recorded "not considered" and "patient refused" as the primary reasons for not using these strategies.

The relatively low rates of use of pharmacotherapy or referral for additional weight management have been demonstrated in previous studies [8, 10], although three major differences in the design of SOCCER compared to previous studies are notable. First, only patients that, in the mind of the physician, unequivocally required weight management were enrolled. Second, physicians were instructed to record data in real time to avoid recall bias and were aware that they were being studied. Given these design factors, one perhaps might have expected the prevalence of drug therapy or use of additional weight management strategies to be higher than that observed. Third, SOCCER also focused on identifying the reasons for not using pharmacotherapy or referring patients, and it is clear that the decision not to proceed with these weight management strategies is related to both patient and physician decisions. Only in a minority of cases were these decisions based upon the presence of specific barriers such as cost. We also found that pharmacotherapy was more likely to be initiated or continued in women, 
TABLE 1: Baseline characteristics.

\begin{tabular}{|c|c|c|c|c|}
\hline & $\begin{array}{c}\text { Overall } \\
n=1788\end{array}$ & $\begin{array}{c}\text { Primary care } \\
n=1300\end{array}$ & $\begin{array}{c}\text { Specialist } \\
n=488\end{array}$ & $\begin{array}{l}P \text {-value for specialist } \\
\text { versus primary care }\end{array}$ \\
\hline Age, mean (SD), y & $52.7(14.3)$ & $52.6(14.6)$ & $52.7(13.6)$ & .94 \\
\hline Weight, mean (SD), kg & $100.6(25.1)$ & $95.8(20.1)$ & $113.6(31.7)$ & $<.01$ \\
\hline BMI, mean (SD), $\mathrm{kg} / \mathrm{m}^{2}$ & $36.1(7.9)$ & $34.8(6.3)$ & $39.8(10.2)$ & $<.01$ \\
\hline Male & $663(37)$ & $460(35)$ & $203(41)$ & .015 \\
\hline Caucasian & $1614(90)$ & $1153(89)$ & $461(95)$ & $<.01$ \\
\hline Employed & $987(55)$ & $737(57)$ & $250(51)$ & .04 \\
\hline Supplemental health insurance & $996(56)$ & $715(55)$ & $281(58)$ & .33 \\
\hline Current smoker & $245(14)$ & $189(15)$ & $56(12)$ & .09 \\
\hline Gout & $75(4)$ & $45(4)$ & $30(6)$ & .02 \\
\hline Cancer & $90(5)$ & $63(5)$ & $27(6)$ & .56 \\
\hline Polycystic ovarian syndrome & $43(2)$ & $24(2)$ & $19(4)$ & .02 \\
\hline Type 2 diabetes & $436(24)$ & $239(18)$ & $197(40)$ & $<.01$ \\
\hline $\begin{array}{l}\text { Impaired fasting glucose/impaired } \\
\text { glucose tolerance }\end{array}$ & $183(10)$ & $89(7)$ & $94(19)$ & $<.01$ \\
\hline Coronary artery disease & $166(9)$ & $79(6)$ & $87(18)$ & $<.01$ \\
\hline Congestive heart failure & $46(3)$ & $21(2)$ & $25(5)$ & $<.01$ \\
\hline Peripheral arterial disease & $38(2)$ & $10(1)$ & $28(6)$ & $<.01$ \\
\hline Stroke & $49(3)$ & $34(3)$ & $15(3)$ & .60 \\
\hline Arrhythmia & $73(4)$ & $45(4)$ & $28(6)$ & .04 \\
\hline Dyslipidemia & $760(43)$ & $518(40)$ & $242(50)$ & $<.01$ \\
\hline Hypertension & $853(48)$ & $582(45)$ & $271(56)$ & $<.01$ \\
\hline Depression & $395(22)$ & $261(20)$ & $134(28)$ & $<.01$ \\
\hline Anxiety & $284(16)$ & $213(16)$ & $71(15)$ & .34 \\
\hline Eating Disorder & $40(2)$ & $19(2)$ & $21(4)$ & $<.01$ \\
\hline Osteoarthritis & $478(27)$ & $289(22)$ & $189(39)$ & $<.01$ \\
\hline Back Pain & $526(29)$ & $347(27)$ & $179(37)$ & $<.01$ \\
\hline Fibromyalgia/chronic fatigue & $88(5)$ & $69(5)$ & $19(4)$ & .21 \\
\hline Gall bladder disease & $127(7)$ & $72(6)$ & $55(11)$ & $<.01$ \\
\hline Abnormal liver enzymes & $60(3)$ & $26(2)$ & $34(7)$ & $<.01$ \\
\hline Gastrointestinal reflux & $357(20)$ & 249 (19) & $108(22)$ & .16 \\
\hline Incontinence & $111(6)$ & $69(5)$ & $42(9)$ & .01 \\
\hline Sleep apnea & $146(8)$ & $54(4)$ & $92(19)$ & $<.01$ \\
\hline Thrombosis/embolism & $25(1)$ & $13(1)$ & $12(3)$ & .03 \\
\hline
\end{tabular}

Data are expressed as no. (\%) unless otherwise noted.

SD: standard deviation; BMI: body mass index.

heavier patients, and those with private drug coverage. This sex difference is consistent with previous studies (both from RCTs and population-based analyses of prescription fills) $[13,18]$. Furthermore, no antiobesity drug is covered under a provincial drug plan in Canada; therefore, the drugs may be unaffordable to many who do not have private coverage.

One limitation of SOCCER is that followup probes examining why the physician failed to consider pharmacotherapy or referral or why the patient refused these actions were not performed. It is certainly possible that physicians may view such interventions as ineffective, may not be familiar with their availability, or may expect that the patient can be successful without further help. Physicians may be aware of data demonstrating poor long-term persistence rates with pharmacotherapy or may not view the benefit/risk ratio of current drugs to be favorable. A recent physician survey reported that physicians might have unrealistic expectations regarding how successfully patients can lose weight [10]. Weight losses of $38 \%$ were categorized as "a dream outcome", and $10 \%$ losses were viewed as "disappointing" despite data demonstrating that such relatively small amounts of weight loss can lead to clinically significant benefits including a reduction in the incidence of type 2 diabetes in high-risk patients $[7,19]$. Conversely, patients may refuse help from healthcare providers because they are more confident that a self-directed weight management plan will be successful [20]. Patients may also not view a physician's office as appropriate venue for weight management and may instead 
TABLE 2: Frequency of use of pharmacotherapy or referral for antiobesity management expertise.

\begin{tabular}{|c|c|c|c|c|c|c|c|c|c|c|c|}
\hline & $\begin{array}{l}\text { Pharmac } \\
\text { used or } \mathrm{r} \\
\text { recomme } \\
n(\%)\end{array}$ & $\begin{array}{l}\text { otherapy } \\
\text { eferral } \\
\text { nded }\end{array}$ & $\begin{array}{l}\text { Pharmacot } \\
\text { not used o } \\
\text { not recom } \\
n(\%)\end{array}$ & $\begin{array}{l}\text { therapy } \\
r \text { referral } \\
\text { mended }\end{array}$ & & & Reason not & recommen & ded $n$ (\% & & \\
\hline Strategy & All & $\begin{array}{l}\text { By } \\
\text { patient } \\
\text { request }\end{array}$ & All & $\begin{array}{l}\text { Patient- } \\
\text { related } \\
\text { reason }\end{array}$ & $\begin{array}{l}\text { Patient } \\
\text { refused }\end{array}$ & $\begin{array}{c}\text { Past } \\
\text { treatment } \\
\text { failed } \\
\end{array}$ & $\begin{array}{c}\text { Not } \\
\text { affordable }\end{array}$ & $\begin{array}{l}\text { Contra- } \\
\text { indicated }\end{array}$ & $\begin{array}{c}\text { Not } \\
\text { feasible }\end{array}$ & $\begin{array}{c}\text { Not } \\
\text { considered }\end{array}$ & Missing \\
\hline Pharmacotherapy & $375(21)$ & $146(39)$ & $1413(79)$ & $792(56)$ & $491(35)$ & $47(3)$ & $167(12)$ & $63(5)$ & $24(2)$ & $618(44)$ & $3(0.02)$ \\
\hline Dietary counseling & $813(46)$ & $257(32)$ & $974(55)$ & $614(63)$ & $300(31)$ & $86(9)$ & $39(4)$ & $9(1)$ & $180(19)$ & $343(35)$ & $17(2)$ \\
\hline Exercise training & $866(49)$ & $291(34)$ & $920(52)$ & $573(62)$ & $216(24)$ & $37(4)$ & $57(6)$ & $18(2)$ & $245(27)$ & $297(32)$ & $50(5)$ \\
\hline Behavioral therapy & $277(16)$ & $49(18)$ & $1508(85)$ & $713(47)$ & $404(27)$ & $28(2)$ & $49(3)$ & $2(0.1)$ & $230(15)$ & $720(48)$ & $75(5)$ \\
\hline $\begin{array}{l}\text { Commercial } \\
\text { programs/popular } \\
\text { diets }\end{array}$ & $261(15)$ & 97 (37) & $1527(85)$ & $626(41)$ & $332(22)$ & $103(7)$ & $116(8)$ & $11(1)$ & $64(4)$ & $853(56)$ & $48(3)$ \\
\hline $\begin{array}{l}\text { Obesity surgery } \\
\left(\mathrm{BMI} \geq 35 \mathrm{~kg} / \mathrm{m}^{2}\right)\end{array}$ & $41(5)$ & $24(59)$ & $742(95)$ & $227(31)$ & $134(18)$ & $4(1)$ & $16(2)$ & $12(2)$ & $61(8)$ & $482(65)$ & $33(4)$ \\
\hline
\end{tabular}

TABle 3: Predictors of initiating pharmacotherap $y^{*}$.

\begin{tabular}{lc}
\hline Variable & Odds ratio (95\% CI) \\
\hline Age & $0.98(0.97-0.99)$ \\
Male & $0.70(0.40-1.23)$ \\
Body mass index & $1.06(1.03-1.08)$ \\
Caucasian ethnicity & $1.52(0.76-3.02)$ \\
Specialist physician & $0.65(0.21-2.0)$ \\
Private drug coverage & $2.36(1.52-3.66)$ \\
Currently employed & $1.16(0.82-1.66)$ \\
Patient-physician gender concordance & $0.71(0.34-1.48)$ \\
Current smoker & $1.61(1.13-2.30)$ \\
Gastroesophageal reflux disease & $1.41(0.97-2.05)$ \\
\hline
\end{tabular}

* Multivariable final adjusted model.

seek alternate methods. In addition, barriers to weight management may limit uptake of weight management strategies. Many patient-related barriers have been identified, including a lack of motivation, failure to recognize obesity as a major health condition, time constraints, low socioeconomic status, intimate saboteurs, and comorbid health conditions (particularly psychological dysfunction and sleep disorders) [21].

Bariatric surgery was recommended in only $5 \%$ of eligible patients in SOCCER. Surgery is the only intervention that consistently leads to substantial weight reduction, and surgery also has been associated with reductions in mortality; improvements in quality of life, and has been shown to be cost effective at commonly cited thresholds. We theorize that physicians may simply fail to consider surgery as a viable treatment option or may be unaware of recent evidence demonstrating that surgery substantially reduces morbidity and mortality in severely obese patients [22]. Conversely, physicians may fail to consider surgery because of the absence of a surgical program in their vicinity or because of the extended (several years) wait times that exist in Canadian surgical programs, although one would have expected physicians to categorize this scenario as "not feasible" rather than "not considered" [23].

Because volunteer physicians practices (only $2 \%$ of the total number of practices contacted) within Canada were enrolled in SOCCER, results may be subject to selection bias and may not be generalizable to all physician practices within and outside this country. Compared to practices that were not interested in participating, practices volunteering to take part likely had higher levels of interest and expertise in weight management and may have been more likely to initiate weight management strategies. Because the study specifically entailed detailing antiobesity management strategies, participants may also have been more likely to use management strategies because they knew these were being measured (i.e., the Hawthorne effect [24]). Therefore, it is probable that the frequency of physician-initiated drug treatment or weight management referral was overestimated compared to "usual care" practices, and, therefore, our results may be considered conservative.

In conclusion, we have demonstrated in this analysis of Canadian physician practice patterns that rates of antiobesity drug use and referral for additional weight management strategies are low. In the majority of cases, either physicians fail to consider these management strategies or patients refuse them. If increased uptake of these guidelineconcordant strategies is to be achieved, both patients and physician-related barriers to weight management will need to be examined and addressed.

\section{Acknowledgments}

This study was funded by an unrestricted Grant from Abbott Laboratories Canada. The sponsor had no role in the design, conduct, or analysis of the study. All authors contributed substantially to either the conception and design of the study or the data acquisition, analysis, and interpretation. R. P. wrote the initial draft of the paper with critical revision for important intellectual content provided by the other authors. R. P. had full access to the data and took responsibility for 
the integrity and accuracy of the data analysis. All authors approved the final version. R. P., A. S., and R. L. are supported by an alternative funding plan from the Government of Alberta and the University of Alberta. D. L. is supported by an alternative funding plan from the Government of Alberta and the University of Calgary.

\section{References}

[1] World Health Organization, "Obesity and Overweight," 2006, http://www.who.int/mediacentre/factsheets/fs311/en/index .html.

[2] D. W. Haslam and W. P. T. James, "Obesity," Lancet, vol. 366, no. 9492, pp. 1197-1209, 2005.

[3] Prospective Studies Collaboration, "Body-mass index and cause-specific mortality in 900000 adults: collaborative analyses of 57 prospective studies," The Lancet, vol. 373, no. 9669, pp. 1083-1096, 2009.

[4] M. L. Daviglus, K. Liu, L. L. Yan et al., "Body mass index in middle age and health-related quality of life in older age: the Chicago heart association detection project in industry study," Archives of Internal Medicine, vol. 163, no. 20, pp. 2448-2455, 2003.

[5] C. L. Birmingham, J. L. Muller, A. Palepu, J. J. Spinelli, and A. H. Anis, "The cost of obesity in Canada," Canadian Medical Association Journal, vol. 160, no. 4, pp. 483-488, 1999.

[6] C. L. Ogden, M. D. Carroll, L. R. Curtin, M. A. McDowell, C. J. Tabak, and K. M. Flegal, "Prevalence of overweight and obesity in the United States, 1999-2004," Journal of the American Medical Association, vol. 295, no. 13, pp. 1549-1555, 2006.

[7] D. C. Lau, J. D. Douketis, K. M. Morrison, I. M. Hramiak, A. M. Sharma, and E. Ur, "2006 Canadian clinical practice guidelines on the management and prevention of obesity in adults and children," Canadian Medical Association Journal, vol. 176, supplement 8, 2007.

[8] D. A. Galuska, J. C. Will, M. K. Serdula, and E. S. Ford, "Are health care professionals advising obese patients to lose weight?" Journal of the American Medical Association, vol. 282, no. 16, pp. 1576-1578, 1999.

[9] A. H. Mokdad, B. A. Bowman, E. S. Ford, F. Vinicor, J. S. Marks, and J. P. Koplan, "The continuing epidemics of obesity and diabetes in the United States," Journal of the American Medical Association, vol. 286, no. 10, pp. 1195-1200, 2001.

[10] S. Phelan, M. Nallari, F. E. Darroch, and R. R. Wing, "What do physicians recommend to their overweight and obese patients?" Journal of the American Board of Family Medicine, vol. 22, no. 2, pp. 115-122, 2009.

[11] J. H. Price, S. M. Desmond, R. A. Krol, F. F. Snyder, and J. K. O'Connell, "Family practice physicians' beliefs, attitudes, and practices regarding obesity," American Journal of Preventive Medicine, vol. 3, no. 6, pp. 339-345, 1987.

[12] A. G. Tsai and T. A. Wadden, "Systematic review: an evaluation of major commercial weight loss programs in the United States," Annals of Internal Medicine, vol. 142, no. 1, pp. 56-66, 2005.

[13] D. Rucker, R. Padwal, S. K. Li, C. Curioni, and D. C. W. Lau, "Long term pharmacotherapy for obesity and overweight: updated meta-analysis," British Medical Journal, vol. 335, no. 7631, pp. 1194-1199, 2007.

[14] Diabetes Prevention Program Research Group, "Within-trial cost-effectiveness of lifestyle intervention or metformin for the primary prevention of type 2 diabetes," Diabetes Care, vol. 26, pp. 2518-2523, 2003.
[15] G. D. Foster, A. P. Makris, and B. A. Bailer, "Behavioral treatment of obesity," The American Journal of Clinical Nutrition, vol. 82, no. 1, pp. 230S-235S, 2005.

[16] L. R. Simkin-Silverman, K. A. Gleason, W. C. King et al., "Predictors of weight control advice in primary care practices: patient health and psychosocial characteristics," Preventive Medicine, vol. 40, no. 1, pp. 71-82, 2005.

[17] An AB, "Performing logistic regression on survey data with the new SURVEYLOGISTIC procedure," 2009, http://www2.sas .com/proceedings/sugi27/p258-27.pdf.

[18] R. S. Padwal, "Trends in obesity and overweight-related office visits and drug prescriptions in Canada, 1998 to 2004," Obesity Research, vol. 13, no. 11, pp. 1905-1908, 2005.

[19] Diabetes Prevention Program Research Group, "Reduction in the incidence of type 2 diabetes with lifestyle intervention or metformin," The New England Journal of Medicine, vol. 346, pp. 393-403, 2002.

[20] G. A. Bray, "Are non-prescription medications needed for weight control?" Obesity, vol. 16, no. 3, pp. 509-514, 2008.

[21] M. Mauro, V. Taylor, S. Wharton, and A. M. Sharma, "Barriers to obesity treatment," European Journal of Internal Medicine, vol. 19, no. 3, pp. 173-180, 2008.

[22] L. Sjöström, K. Narbro, C. D. Sjöström et al., "Effects of bariatric surgery on mortality in Swedish obese subjects," New England Journal of Medicine, vol. 357, no. 8, pp. 741-752, 2007.

[23] R. S. Padwal and A. M. Sharma, "Treating severe obesity: morbid weights and morbid waits," Canadian Medical Association Journal, vol. 181, no. 11, pp. 777-778, 2009.

[24] R. H. Franke and J. D. Kaul, "The Hawthorne experiments: first statistical interpretation," American Sociological Review, vol. 43, pp. 623-643, 1978. 


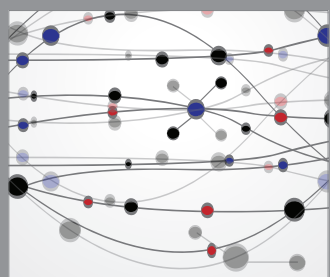

The Scientific World Journal
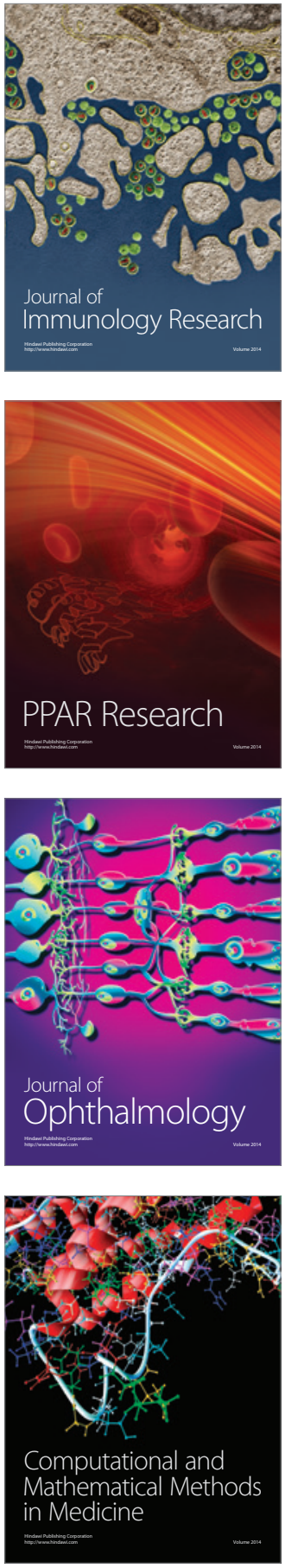

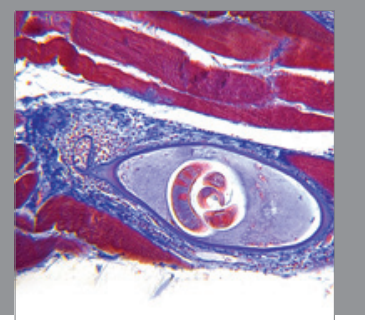

Gastroenterology

Research and Practice
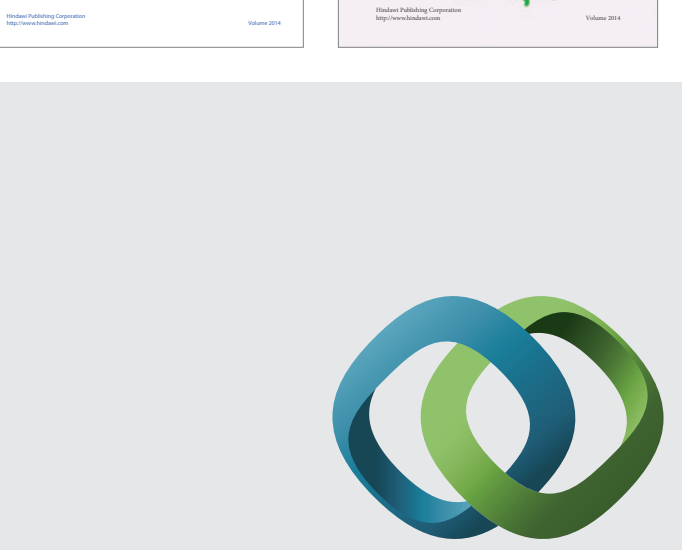

\section{Hindawi}

Submit your manuscripts at

http://www.hindawi.com
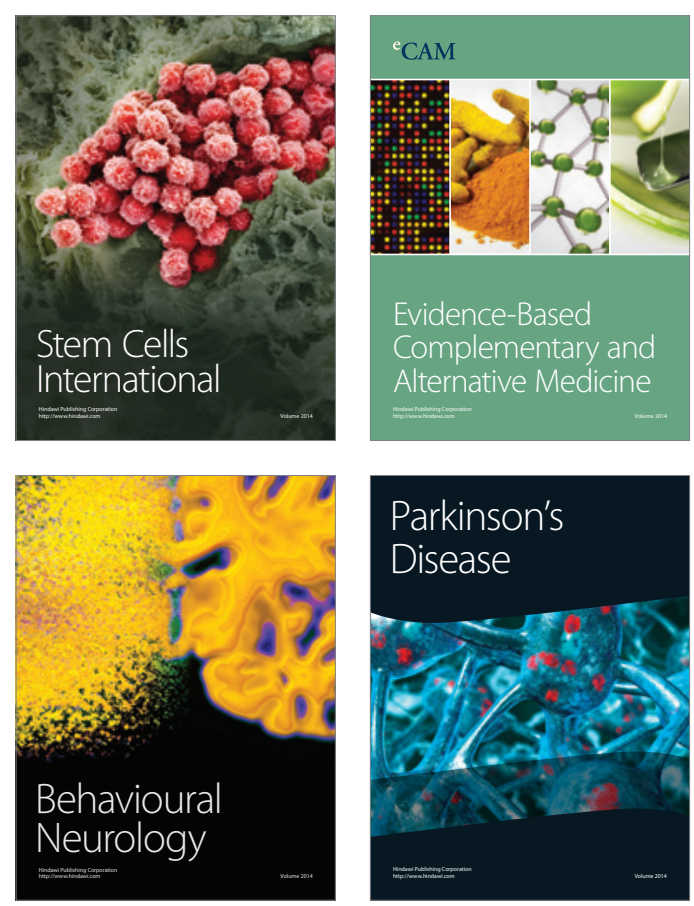

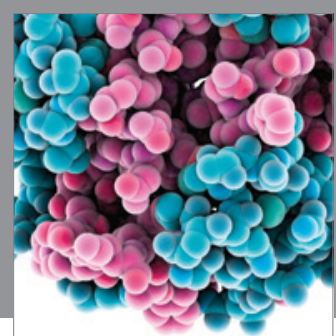

Journal of
Diabetes Research

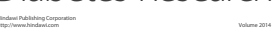

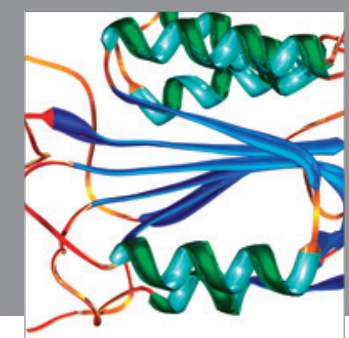

Disease Markers
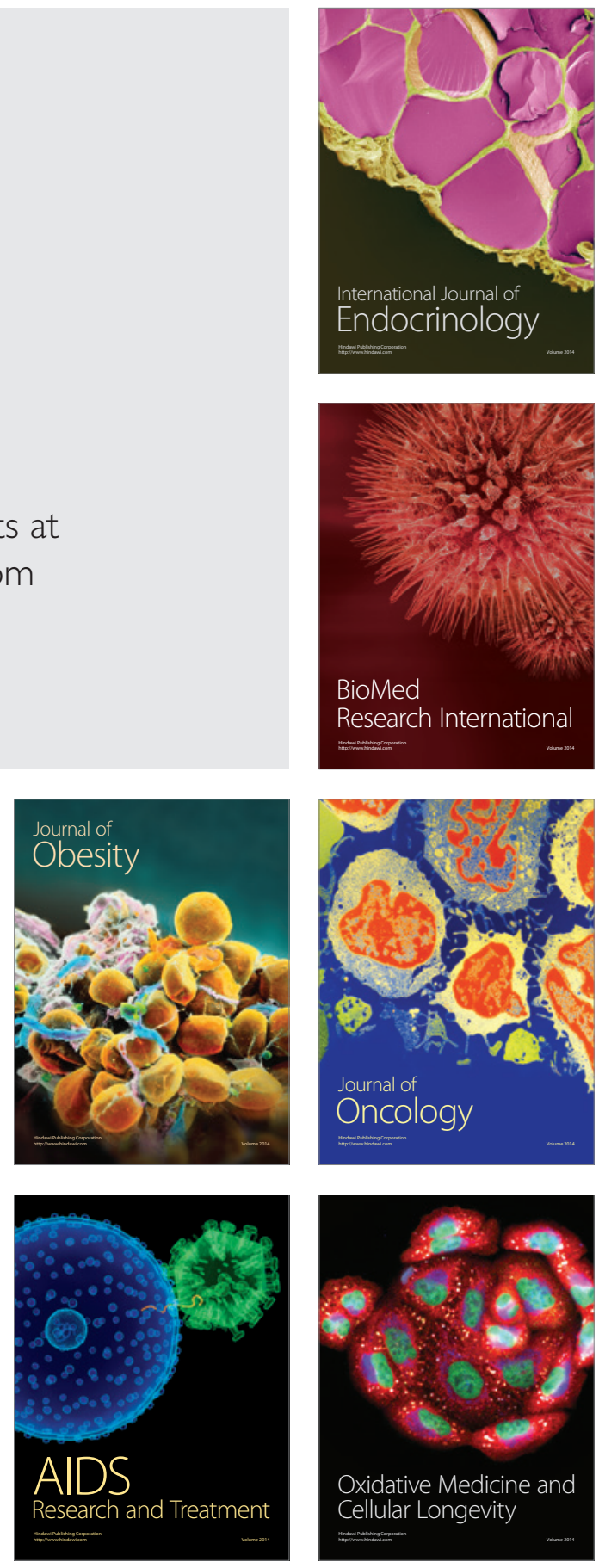